Care pattern and behavioural status of preschool children of employed mothers in $\mathrm{MOH}$ area Kaduwela

\section{Samarakkody $^{1}$, MW Gunathunga ${ }^{2}$}

\section{Abstract \\ Introduction}

The objective of this study was to assess the influence of care patterns on behavioural status of pre school children of employed mothers.

\section{Methodology}

A descriptive cross sectional study was conducted to assess the influence of care patterns, on behaviour of pre school children of employed mothers in the $\mathrm{MOH}$ area, Kaduwela. Parents or principal care givers of pre-school children getting two types of care (home care and in day care centers) were interviewed using a pre-tested, interviewer administered questionnaire.

Results

The educational level of the caregivers of the day care group was significantly higher than the home care group. The prevalence of behaviour abnormalities of the study group was $10.75 \%$. The study revealed a significantly higher proportion of behavioural abnormalities among children looked after at their own home than those who were looked after in daycare centres. The children looked after in daycare centres had more advanced social interactions than the home cared group. A higher proportion of children cared at home showed abnormal behaviours related to eating, sleeping, personal interactions and communication than children looked after in day care centres. Irritability was shown by higher percentage of children looked after in day care centres.

\section{Conclusions}

Pre-school children looked after in their homes showed more behavioural problems than those looked after at day care centers. The effect of care pattern on behaviour of pre-school children depends on the educational level of the substitute care giver.

\section{Key words}

pre-school children; home care; day care centers; behavioural abnormalities

1. Ministry of Health, Colombo 8 .

2. Senior Lecturer, Department of Community Medicine, Faculty of Medicine, University of Colombo.

\section{Introduction}

'Children's early experience affect not only the quality of their present lives but also their later ability to learn and reason' (1). There is a rapid development of the brain during pre-school age and, by the time a child reaches five years of age, $90 \%$ of the brain cells are formed. This explosive growth of 'brain cells follows the formation of synapses that control the child's behavioural pattern and psychosocial development. Therefore, adequate nutrition and a stimulating environment during this period contribute enormously to the enhancement of the cognitive development of the child (2).

The family and the immediate environment are fundamental for ensuring these needs of the child. In Sri Lanka, mothers and grand parents were the traditional caregivers of their children during their childhood. With the introduction of the free education scheme in 1945 , there was a rapid expansion of literacy and educational levels of women. This resulted in wider participation of women in formal and non-formal economic activities. The female labour force has increased from 570,000 in 1970 to $2,510,000$ in 2003 and this trend will continue at an even faster rate (3).

Along with this economic transition, internal migration took place in search of employment opportunities. This disturbed the extended family system, where grand parents and relatives played a vital role in caring for young children. As a result, a larger proportion of children experienced substitute care.

The purpose of this study was to determine what relationship, if any, care patterns had on behaviour of pre-school children.

\section{Methodology}

A community based descriptive cross sectional study was conducted in the Medical Officer of Health area Kaduwela, where rapid urbanization had taken place leading to a high proportion of employed females.

Two hundred children (36-59 months age) of employed mothers who were looked after at day care centers were selected using a three stage random sampling method (day care group). A comparative group of pre-school children of employed mothers looked after in their own homes, was selected from the neighbourhood of each child who received day care in a center by matching age and sex.

The selected pre school children fulfilled the following criteria.

1. Their mothers were employed out of home for more than 30 hours per week.

2. They had received the present care pattern for 
not less than six months from the date of the interview.

Pre-school children whose mothers engaged in shift work and those with chronic disease confirmed by a diagnosis card were excluded from the study.

The first author and three trained interviewers visited the homes of the selected children on weekends and public holidays for data collection and interviewed the mother or in the absence of the mother, the principal caregiver of the child. The data collection was done by an interviewer administered, pre-tested structured questionnaire. It consisted of variables on demographic factors of the child, socio-economic status of parents and details of the arrangements for care of the child. The behavioural status of the child was assessed using the Pre-school Behaviour Screening Check List (PBSCL), which has previously been validated to be used in Sri Lanka $(4,5)$.

\section{Results}

As the two groups were matched for age and sex, the age and sex distribution was similar in both groups. The age range was $36-59$ months and the highest proportion of children in both groups $(68 \%$ in home care and $69 \%$ in institutional care) were in the $36-47$ months age group. There were $59 \%$ females and $41 \%$ males in each care group.

\section{Birth related factors}

Table 1- Distribution of pre school children by birth related factors and care arrangement

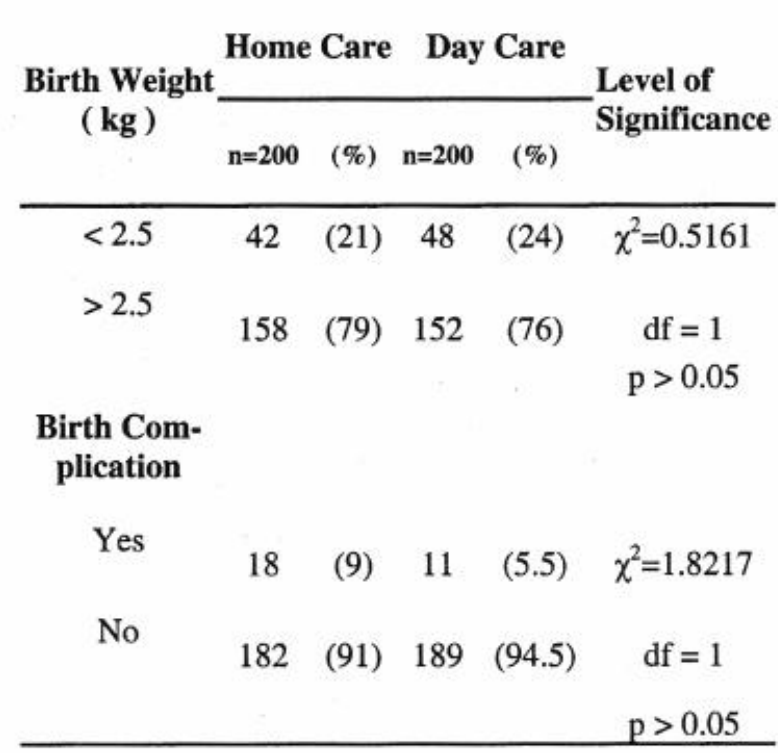

Table 1 gives the distribution of birth weight and presence or absence of birth complication by care arrangement. Two groups were comparable in respect of these factors.

\section{Educational status of parents and caregiver}

A great majority $(36 \%)$ of fathers of home care group had studied up to diploma or degree level which was significantly high $(\mathrm{p}<0.05)$ compared to diploma or degree holding fathers in day care group $(24.5 \%)$ (Table 2 ).

Sixty seven $(33.5 \%)$ mothers of the home cared group had a diploma or a degree while only 58 (29\%) mothers of day care children had the same level of education. Five $(2.5 \%)$ mothers of home care group and $9(4.5 \%)$ mothers of day care group had studied only up to primary level (Table 2)

Twenty one percent of caregivers of the home care group had not gone to school. The majority $(42 \%)$ of caregivers of the day care group had diploma or a degree, while this level of education had been achieved only by 2.5 percent of care givers of the home care group. The educational level of the caregivers of the day care group was significantly higher than the home care group (Table 2).

\section{Presence of behaviour abnormality}

Fifteen percent of children in home care group showed behaviour abnormality (Table 3 ). In the day care group, only 6.5 percent of children showed abnormal behaviour the difference being statistically significant $(\mathrm{p}<0.01)$. The total prevalence of behaviour abnormality in the study group was $10.75 \%$. 
Table 2. Comparison of educational status of the parents and caregiver by care arrangement

\begin{tabular}{|c|c|c|c|}
\hline \multirow{2}{*}{ Educational level } & Home Care & Day care & \multirow{2}{*}{$\begin{array}{c}\text { Level of Signifi- } \\
\text { cance }\end{array}$} \\
\hline & $\mathrm{n}=\mathbf{2 0 0}(\%)$ & $\mathrm{n}=\mathbf{2 0 0}(\%)$ & \\
\hline \multicolumn{4}{|l|}{ Education level of the father } \\
\hline \multirow[t]{2}{*}{ Primary level } & $5(2.5)$ & $3(1.5)$ & \\
\hline & & & $\begin{array}{l}\chi^{2}=9.9107 \\
\mathrm{df}=4\end{array}$ \\
\hline Secondary level & $5(2.5)$ & $28(14)$ & $\mathrm{p}<0.05$ \\
\hline Completed OL & $42(21)$ & $38(19)$ & \\
\hline Completed AL & $76(38)$ & $82(41)$ & \\
\hline Diploma or Degree & $72(36)$ & $49(24.5)$ & \\
\hline
\end{tabular}

\section{Education Level of the Mother}

$\begin{array}{lcc}\text { Primary level } & 5(2.5) & 9(4.5) \\ \text { Secondary level } & 6(3) & 9(4.5) \\ \text { Completed OL } & 35(17.5) & 56(28) \\ \text { Completed AL } & 87(43.5) & 68(34) \\ \text { Diploma or Degree } & 67(33.5) & 58(29)\end{array}$

$\chi^{2}=9.57$

$\mathrm{df}=4$

$\mathrm{p}<0.05$

Diploma or Degree $\quad$ 67(33.5) 58(29)

\section{Educational Level of the care giver}

\begin{tabular}{lccl} 
Not gone to school & $42(21)$ & $3(1.5)$ & \\
Primary level & $22(11)$ & $4(2)$ & $\begin{array}{l}\chi^{2}=57.51 \\
\text { Df }=5\end{array}$ \\
Secondary level & $35(17.5)$ & $13(6.5)$ & $\mathrm{p}<0.01$ \\
Completed OL & $69(34.5)$ & $62(31)$ & \\
Completed AL & $27(13.5)$ & $34(17)$ & \\
Diploma or Degree & $5(2.5)$ & $84(42)$ & \\
\multicolumn{1}{r}{$\quad$ Total } & 200 & 200 & \\
\hline
\end{tabular}

Table 3 - Distribution of pre school children by the score of PBSCL and care arrangement

\begin{tabular}{lccc}
\hline $\begin{array}{c}\text { PBSCL } \\
\text { Score }\end{array}$ & $\begin{array}{c}\text { Care of child } \\
\text { Home Care }\end{array}$ & $\begin{array}{c}\text { Day Care } \\
\mathbf{n = 2 0 0}(\%)\end{array}$ & Total \\
\hline $\begin{array}{c}\text { Less than } 13 \\
\text { (normal } \\
\text { behaviour) }\end{array}$ & $170(85)$ & $187(93.5)$ & 357 \\
$\begin{array}{l}\text { More than } 13 \\
\text { (abnormal } \\
\text { behaviour) }\end{array}$ & $30(15)$ & $13(6.5)$ & 43 \\
\hline & & \\
\hline$\chi^{2}=7.5305 \mathrm{df}=1 \mathrm{p}<0.01$
\end{tabular}

Presence of each abnormal behaviour type of PBSCL

A higher percentage of home cared children showed abnormal behaviours related to eating (poor appetite $15.5 \%$, faddy of food $18 \%$ ), sleeping (difficult to fall asleep $8 \%$, wakes at night $10 \%$ ), interaction (get on badly with siblings $4.5 \%$, difficult to play with others $13.5 \%$ ) and communication (no recognizable words $12 \%$ ) than institution cared children (Table 4).

Behaviours related to sphincter control (night wetting, day wetting and soiling) were distributed almost similarly in both groups. Irritability and temper tantrums were shown by higher percentage of institution cared children than home cared children (Table 4). 
Table 4-Distribution of pre school children by each abnormal behaviour type of PBSCL and care arrangement

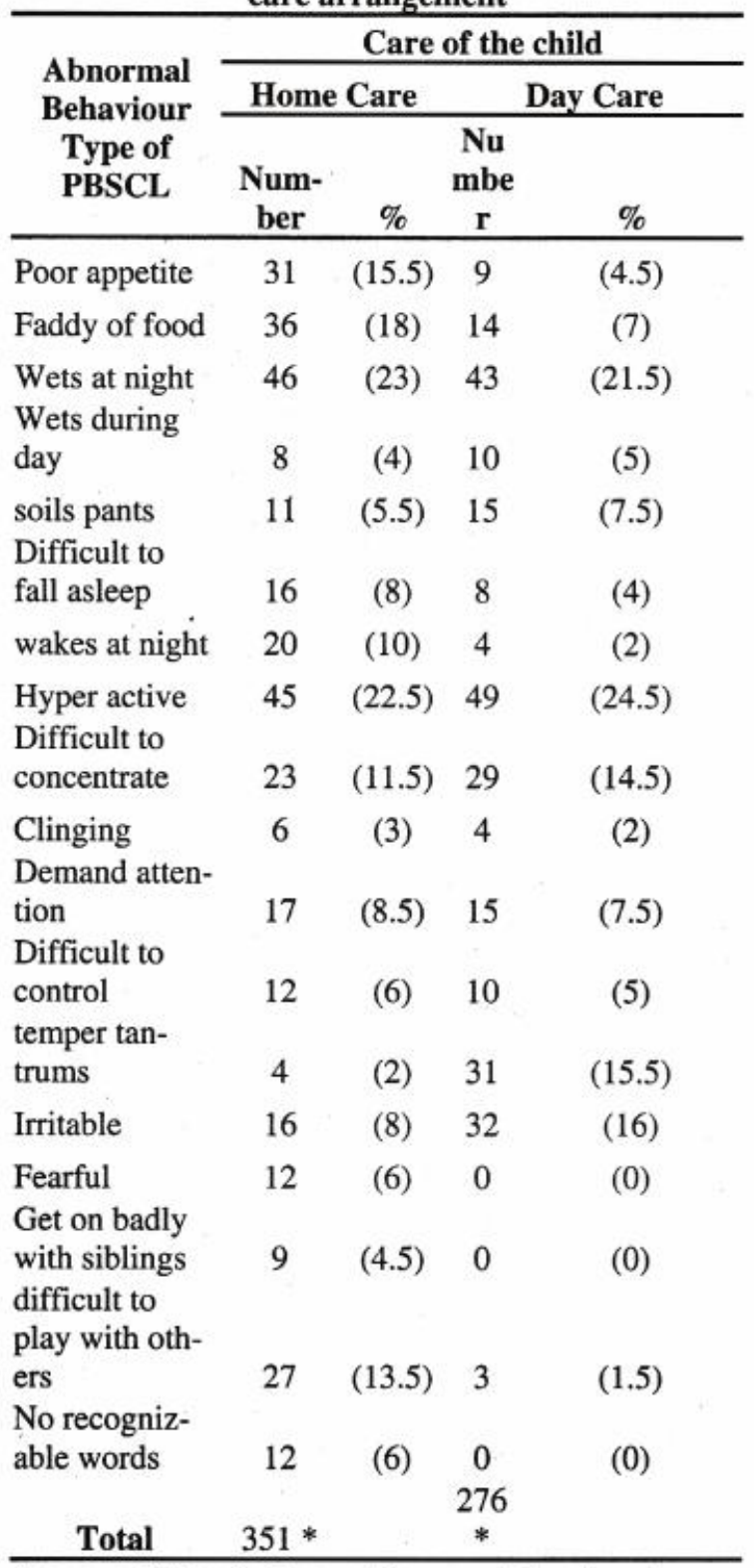

*some children had more than one behaviour abnormality

\section{Discussion}

Working mothers provide a variety of arrangements for their children's care. The majority leave their pre-school children at home to be cared for by a relative or sitter while they work. The rest leave their young ones at day care centres. As the effects of maternal employment on the child's development depend, to a large extent, on the quality of substitute care, it is important to consider how care arrangement will affect future generations.
The best approach to assess the effects of care arrangement on behaviour of pre school children would be through a longitudinal study design, where the two study groups are followed up for a period of time, and the effect of 'exposure' (care arrangement) on them measured (6). The possibility of changes in the care arrangement over a period of time favoured a cross sectional study design.

The present study was conducted in the $\mathrm{MOH}$ area Kaduwela, one of the nine $\mathrm{MOH}$ areas of the Colombo District. This area had been subjected to rapid urbanization with establishment of new housing complexes and an increase in the number of employed females. Studies have shown that, age, sex, and physical environment affect behaviour of pre-school children (7). In the present study, the confounding effects of such variable have been minimised by matching the two study groups on age, sex and the area of residence (8). The disadvantage with matching is that when several variables are being controlled, finding matching pairs becomes. This results in restriction of population coverage and thus restricts the generalisability of the conclusions. Therefore, the number of matching criteria was restricted to three variables, age, sex and the area of residence (9).

There was no statistically significant difference in the distribution of birth weight and presence of birth complication in the two study groups.

The educational status of parents greatly affects the behaviour of the preschool children (10). The present study showed that a significantly higher $(\mathrm{p}<0.05)$ level of education among parents of home cared group compared to parents of day care group. Conversely, this study further reveals a significantly higher level of education among caregivers at institutions than those at home.

The reason for the higher proportion $(43.5 \%)$ of diploma or degree holders among the caregivers of day care centers may be due to the fact that diploma courses on Montessori Education or on Early Childhood Care and Development, are accepted qualifications to work in such institutions.

The disruption of the psychosocial development of the preschool child is most often manifested as a behavioural abnormality (2). In the present study the prevalence of behavioural abnormality of the entire study group was $10.75 \%$. A lower prevalence $(8.3 \%)$ of behavioural abnormality among children of the 2-5 year age groups in the Deputy Provincial Director of Health Division of Colombo, was observed in a previous study (4). 
Table 4-Distribution of pre school children by each abnormal behaviour type of PBSCL and care arrangement

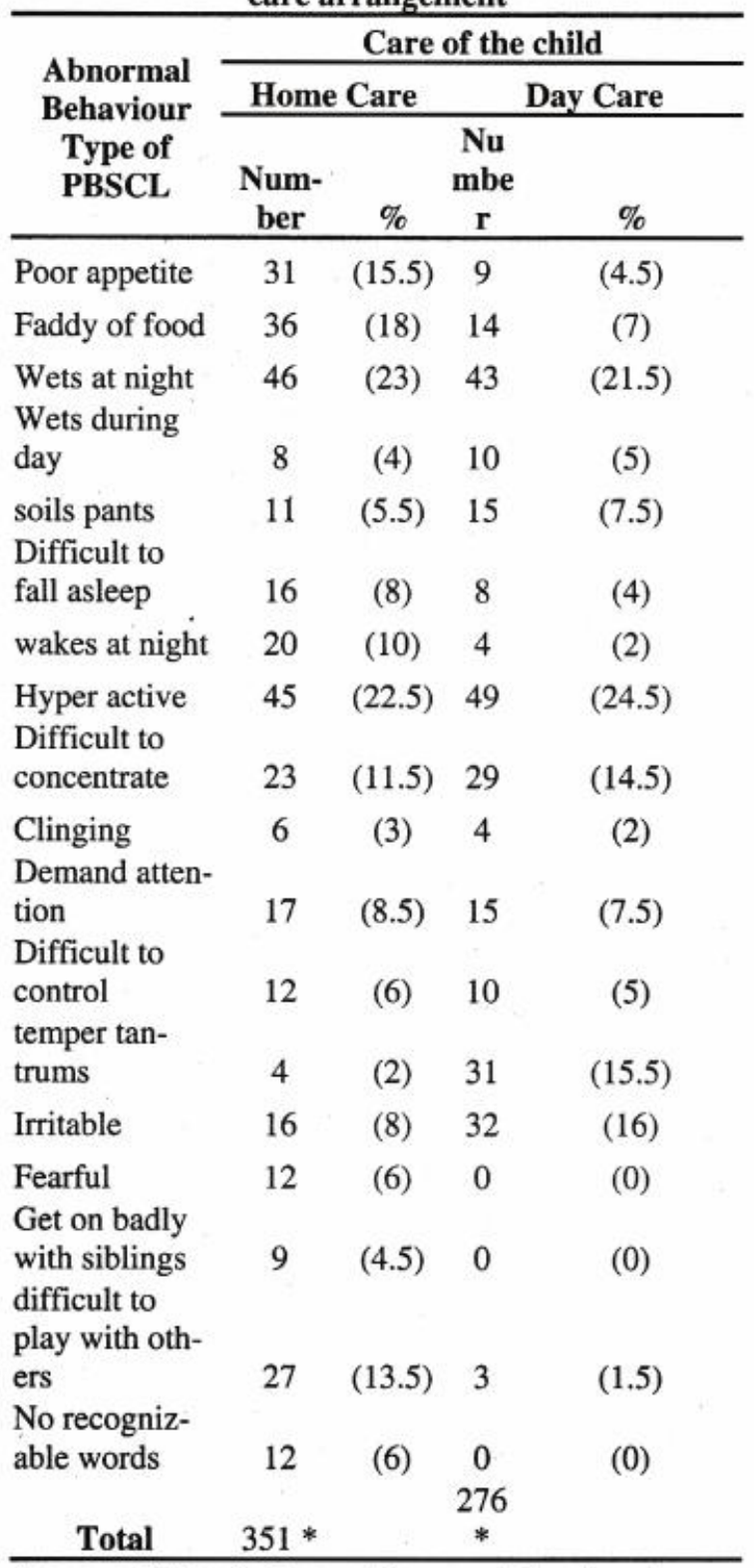

*some children had more than one behaviour abnormality

\section{Discussion}

Working mothers provide a variety of arrangements for their children's care. The majority leave their pre-school children at home to be cared for by a relative or sitter while they work. The rest leave their young ones at day care centres. As the effects of maternal employment on the child's development depend, to a large extent, on the quality of substitute care, it is important to consider how care arrangement will affect future generations.
The best approach to assess the effects of care arrangement on behaviour of pre school children would be through a longitudinal study design, where the two study groups are followed up for a period of time, and the effect of 'exposure' (care arrangement) on them measured (6). The possibility of changes in the care arrangement over a period of time favoured a cross sectional study design.

The present study was conducted in the $\mathrm{MOH}$ area Kaduwela, one of the nine $\mathrm{MOH}$ areas of the Colombo District. This area had been subjected to rapid urbanization with establishment of new housing complexes and an increase in the number of employed females. Studies have shown that, age, sex, and physical environment affect behaviour of pre-school children (7). In the present study, the confounding effects of such variable have been minimised by matching the two study groups on age, sex and the area of residence (8). The disadvantage with matching is that when several variables are being controlled, finding matching pairs becomes. This results in restriction of population coverage and thus restricts the generalisability of the conclusions. Therefore, the number of matching criteria was restricted to three variables, age, sex and the area of residence (9).

There was no statistically significant difference in the distribution of birth weight and presence of birth complication in the two study groups.

The educational status of parents greatly affects the behaviour of the preschool children (10). The present study showed that a significantly higher $(\mathrm{p}<0.05)$ level of education among parents of home cared group compared to parents of day care group. Conversely, this study further reveals a significantly higher level of education among caregivers at institutions than those at home.

The reason for the higher proportion $(43.5 \%)$ of diploma or degree holders among the caregivers of day care centers may be due to the fact that diploma courses on Montessori Education or on Early Childhood Care and Development, are accepted qualifications to work in such institutions.

The disruption of the psychosocial development of the preschool child is most often manifested as a behavioural abnormality (2). In the present study the prevalence of behavioural abnormality of the entire study group was $10.75 \%$. A lower prevalence $(8.3 \%)$ of behavioural abnormality among children of the 2-5 year age groups in the Deputy Provincial Director of Health Division of Colombo, was observed in a previous study (4). 
In the present study, there was a significantly higher proportion of children with abnormal behaviour in the home care group than in the institutional care group. Similar results had been shown in a study conducted in Sweden, comparing group care and family child rearing patterns (11).

The score obtained for the individual components of the Pre School Behaviour Check List (PSBCL) was analyzed in relation to the care arrangement. In comparison with children looked after at home, a higher percentage of children at day care centers demonstrated behaviours such as irritability and temper tantrums.

Among the home cared group, night wetting was the commonest type of abnormal behaviour. Poor appetite, faddy of eating, poor relationship with others (siblings and peers) and poor communication (difficulty to understand words), were present in a higher percentage of children cared for at home than those cared for at day care centers. Some abnormal behaviour forms such as demanding attention and difficulty in concentration occurred in almost equal percentages in both care groups. The fact that the present study assessed behavioural abnormality based only on information given by the mother or the principal caregiver without observation by a trained observer, need to be considered in interpreting the results.

Previous studies had shown that the children looked after at day care centers were at an advanced level of social interactions than children cared for at home (12). This is in conformity with the results of the present study.

\section{Acknowledgements}

We are grateful to the late Mr. K. Perera, Mr. M. Samarakkody, Mr. M.S. Liyanage and late Mr. A.G.C.C. Perera for their assistance in organizing field logistics.

\section{References}

1. The State of the World's Children 2001, UNICEF, London.

2. Santrock JW, Early childhood, Children, $5^{\text {th }}$ Edition, McGraw Hill Publishers, Boston, 1997.

3. Population Statistics of Sri Lanka, Population Information Centre, Population Division, Ministry of Health, Highways and Social Services, 1996.

4. Ariyarathana AKSK. An evaluation of an intervention programme on child mental health activities (Dissertation). Post Graduate Institute of Medicine: University of Colombo, 1996.
5. Richman N, Graham PA. Behaviour screeni questionnaire for use with three year old $\mathrm{ch}$. dren; preliminary findings, Journal of Chila Psychology and Psychiatry, 1971: 12:5-33.

6. Bee H. The Developing Child, $5^{\text {th }}$ edition, Harper and Row Publishers, New York 1989.

7. Bradley RH, Caldwell BM. The relation of ifant's home environment to mental test performance at 54 months; a follow-up study. Child Development. 1976:47; 1172-1174.

8. Hennekens $\mathrm{CH}$, Buring PHJE. Epidemiology In Medicine, Little Brown and Company, Boston, Toronto, 1987.

9. Abramson JH, Abramson Z.H. Survey Methods in Community Medicine, Churchill Livingstone, London, 1999.

10. Choudhry M, Rao KV. Relative importance of factors associated with mental function of preschool children, Indian Journal of Medical Research, 1983: 78; 365-372.

11. Melhuish EC, Mooney A, Martin S, Lioyd E. Type of child care at 18 months; differences in interactional experience. Journal of Child Psychology and Psychiatry, 1990:31(6); 849-859.

12. Cochran MMA. Comparison of Group Care and Family Child Rearing Patterns in Sweden. Child Development, 1977: 48; 702-707. 